\title{
Entretecendo leituras: 0 protagonismo de mulheres negras e o uso de cordéis nas aulas de história da EJA do Colégio de Aplicação da UFRGS
}

Interwoven readings: Black women's agency and the use of "cordel" literature in History lessons in the "Youth and Adult Education" Program (EJA) at the Application School of UFRCS

Vanderlei Machado* Ana Paula Zini de Abreu**

\section{Resumo}

$\mathrm{O}$ artigo apresenta uma experiência desenvolvida no ensino médio da Educação de Jovens e Adultos (EJA) do Colégio de Aplicação da UFRGS, no âmbito do projeto de extensão "Programa de Educação Continuada de Professores", que tem entre seus objetivos ampliar a formação de recém-graduados e/ou professores de escolas públicas e privadas. O programa proporciona discussões teóricas e a prática docente orientada por professores efetivos do Colégio de Aplicação. Na atividade relatada, buscamos criar espaços de discussão sobre a presença das mulheres negras na história do Brasil. Utilizamos como materiais pedagógicos um texto da jornalista Jarid Arraes publicado na revista Fórum e vários cordéis escritos por
Abstract

This article discusses an experience developed in the "Youth and Adult Education" Program (EJA) of the Application School of UFRGS, within the extension project "Continued Teacher Training Program", whose objectives include providing training opportunities for new graduates and/or teachers from public and private schools. The program provides theoretical discussions and the practice of teaching guided by teachers of the Application School. In the activity reported, we create spaces for discussion about the presence of black women in Brazilian History. Pedagogical materials used were a text published by the journalist Jarid Arraes in the magazine Fórum, and several of her "cordel" texts

\footnotetext{
** Doutor em História atuando no Colégio de Aplicação da Universidade Federal do Rio Grande do Sul (UFRGS). Porto Alegre, RS, Brasil. vandermachado@hotmail.com

** Graduada em História pela PUC-RS, com Aperfeiçoamento em Prática Docente (Programa de Educação Continuada) no Colégio de Aplicação/UFRGS, sob orientação do professor Vanderlei Machado. Porto Alegre, RS, Brasil. ana.zini@acad.pucrs.br
} 
ela e que versam sobre mulheres negras que se destacaram na história do Brasil. Além do conhecimento do protagonismo das mulheres negras na história, visamos desenvolver entre os alunos competências de leitura, interpretação e escrita. Palavras-chave: ensino de História; História das mulheres negras no Brasil; literatura de cordel. about black women who stood out in Brazilian History. Besides the knowledge of the protagonism of black women in History, we aimed to develop reading, interpretation and writing skills among the students.

Keywords: teaching History; History of Black Women in Brazil; "cordel” literature.

O presente artigo ${ }^{1}$ relata experiência de ensino desenvolvida em uma turma de primeiro ano do Ensino Médio na Educação de Jovens e Adultos (EJA) do Colégio de Aplicação da UFRGS, em novembro de 2015, no âmbito do Curso de Aperfeiçoamento em Prática Docente (Programa de Educação Continuada, 2015). Nesse trabalho, que girou em torno do artigo "Heroínas negras na história do Brasil", escrito pela cordelista Jarid Arraes, e da leitura de cordéis que abordam a mesma temática, buscamos criar espaços de discussão sobre a participação e o protagonismo das mulheres negras na história do Brasil.

O relato que segue é composto por: a) apresentação do perfil da turma e de dados sobre seu conhecimento prévio em torno do tema; b) diálogo com a legislação relativa à educação, ensino de história e cultura africana e afro-brasileira e estudos de gênero na educação básica; c) descrição da atividade com um texto disparador da questão da invisibilidade das mulheres negras na escola e na sociedade; d) historicização da literatura de cordel no Brasil; e) apresentação de alguns trabalhos acadêmicos e a maneira como abordam a história das mulheres negras no Brasil; f) por último, relataremos a experiência com o uso de cordéis em sala de aula.

Os/as estudantes que procuram a EJA do CAp/UFRGS, conforme constatamos em questionário preenchido no início do semestre letivo, são, em sua maioria, pessoas que pararam de estudar há muito tempo; que trabalham em horário comercial e desejam retomar os estudos com a expectativa de ingressar em cursos técnico-profissionalizantes e/ou no ensino superior. A idade dos/as estudantes da turma em questão variava entre 18 e 60 anos.

Numa conversa que antecedeu a experiência de ensino em tela, na qual buscamos verificar os conhecimentos prévios dos/das estudantes, afirmavam 
desconhecer a presença de mulheres negras na história do Brasil. Percebeu-se ainda o quanto estava presente um conhecimento no qual sobressaíam as datas históricas, alguns acontecimentos políticos e os chamados heróis nacionais, em sua maioria homens brancos que ocupavam postos de comando. Percebida essa visão predominante da história, cresceu nossa motivação inicial de abordar a história das mulheres negras.

A maioria dos/das estudantes da turma em que desenvolvemos a atividade interrompeu seus estudos antes dos anos 1990. Naquele período, o Brasil ainda não contava com uma legislação que recomendasse ou tornasse obrigatório o ensino da história e da cultura afro-brasileira, apesar da luta do movimento negro, desde os anos 1970, pela inserção dessa temática em sala de aula.

Como nos informa Anderson Ribeiro Oliva (2012, p.32), um dos objetivos principais da Educação Básica no Brasil é o de que estudantes e professores possam "reconhecer e valorizar a 'pluralidade do patrimônio sociocultural brasileiro', e, ao mesmo tempo, conhecer também os 'aspectos socioculturais de outros povos ... posicionando-se contra qualquer discriminação"”. O mesmo autor nos lembra, ainda, que a Lei de Diretrizes e Bases da Educação Nacional (LDB), Lei 9.394/1996, determina que o ensino de História do Brasil nas escolas leve em conta as contribuições de diferentes culturas e etnias para a formação do povo brasileiro (Oliva, 2012, p.32).

A Lei 10.639/03, sancionada em 2003, estabelece a obrigatoriedade do Ensino de História e Cultura Afro-Brasileira e Africana no currículo da Educação Básica. Essa Lei, nos lembra Cláudia Campos, inseriu a discussão sobre os "princípios e valores das africanidades brasileiras" no cotidiano escolar com o intuito de que "as diferenças e as diversidades sejam respeitadas" (Campos, 2012, p.133). Conforme a autora, "o professor voltado para as pedagogias de combate ao racismo e à discriminação deve criar estratégias que abordem essas complexidades existentes na sociedade" (p.134).

A obrigatoriedade do ensino de história e cultura africanas e afro-brasileiras, segundo Júnia Sales Pereira e Luciano Magela Roza, e as “pressões postas no tempo presente, sobretudo aquelas advindas do combate ao racismo, forçam a uma reconfiguração das narrativas históricas com repercussões nas formas de abordagem da história do Brasil” (Pereira; Roza, 2012, p.92). Nos últimos anos, notadamente a partir da sanção da Lei 10.639/03, é crescente o 
número de publicações voltadas para o ensino de história e cultura africanas e afro-brasileiras.

A existência dessas leis está ligada às lutas do movimento negro em favor de uma educação que combata todas as formas de racismo. Da mesma forma, historiadores/as ligados à História das Mulheres e à história das relações de gênero têm reivindicado a inserção dessas temáticas na Educação Básica visando contribuir para o combate das desigualdades existentes entre homens e mulheres e os preconceitos de gênero. Em 1996, o MEC lançou os Parâmetros Nacionais Curriculares (PCNs), voltados ao Ensino Fundamental. Nesse documento, o tema das relações de gênero figura como um dos "eixos transversais" a serem discutidos em sala de aula. A partir de 2008, os livros didáticos de História, selecionados pelo Plano Nacional do Livro Didático para o Ensino Médio, teriam entre seus critérios de escolha abordar "criticamente as questões de sexo e gênero" (PNLEM/2008, 2007, p.15).

Várias pesquisas que analisam os livros didáticos de história, tanto do ensino fundamental quanto do ensino médio, demonstram que os estudos de gênero estão ausentes desse material didático e que a história das mulheres, quando aparece, é "nas bordas e margens das produções didáticas, em quadros específicos e em situações pontuais, sem evidentes impactos sobre os processos históricos" (Mistura; Caimi, 2015, p.241-243). Com relação às mulheres negras, "estas aparecem como mucamas - em serviços domésticos”, relacionadas com a Lei do Ventre Livre ou em "situações de desordem social, trazidas pela escravidão" (ibidem). Ou seja, as mulheres africanas e afrodescendentes figuram nas narrativas dos livros didáticos apenas como vítimas da escravidão.

Levando em conta esse quadro, passamos a narrar os passos da experiência realizada. Como dissemos, ela fez parte do Curso de Aperfeiçoamento em Prática Docente (Programa de Educação Continuada) do Colégio de Aplicação/ UFRGS. O Programa tem por objetivos: (a) oportunizar novas possibilidades de formação a recém-graduados e/ou professores de escolas públicas e privadas, ampliando o espaço para parcerias institucionais, contemplando profissionais que desejem participar do processo de ação-reflexão sobre o movimento educacional na busca de inovações e perspectivas docentes para a superação dos desafios educacionais que hoje se impõem; (b) possibilitar a troca de experiências e discussões teórico-metodológicas que possibilitem atualização e análise crítica na busca de alternativas de ações voltadas para uma educação 
contextualizada; e (c) Oferecer aos graduados, egressos das licenciaturas, a discussão teórica e o exercício de prática docente orientada por professores efetivos do Colégio de Aplicação e, assim, contribuir para o aperfeiçoamento técnico e pedagógico do profissional em educação.

Nesse programa, o professor de Educação Continuada segue o Plano de Ensino elaborado pelo professor orientador, preparando seus Planos de Aulas com base nesse documento. O professor tutor avalia e sugere, quando necessário, modificações nos materiais pedagógicos elaborados pelo professor de Educação Continuada. A proposta em tela foi planejada e desenvolvida conjuntamente pelo professor Orientador e pela professora de Educação Continuada.

A inserção da história das mulheres negras em nossas aulas foi desenvolvida em dois momentos. Num primeiro, trabalhamos um artigo escrito por Jarid Arraes, intitulado "Heroínas negras na história do Brasil" (Arraes, 2015), e no segundo exploramos um conjunto de cordéis escritos pela mesma autora. Jarid Arraes nos informa, em texto publicado na internet, que é filha e neta de cordelistas, nascida na região do Cariri, no sertão do Ceará. De acordo com sua própria narrativa, aprendeu "com a mãe a ser feminista" e com o pai, "a arte de escrever cordéis". ${ }^{2}$ Em seus diversos cordéis - ela é autora de mais de trinta títulos - Jarid aborda temas como feminismo, machismo, racismo e homofobia. Ela também atua como jornalista, com uma coluna na revista Fórum, onde escreve sobre feminismo, questões raciais, diversidade sexual e de gênero e direitos humanos.

Buscando auxiliar a análise do artigo mencionado, elaboramos um roteiro para que os/as estudantes extraíssem do texto algumas ideias principais e para orientação do debate (Anexo I). A leitura do artigo tinha entre seus objetivos apresentar informações sobre a maneira como as mulheres negras contribuíram na luta contra a escravidão, questionar a vertente eurocêntrica apresentada pela história ensinada nas escolas e dar visibilidade ao protagonismo das mulheres negras na história. Ao criticar a ausência dessas mulheres, Jarid afirma que

Nosso papel é fazer com que essas mulheres negras sejam conhecidas e seus feitos sejam estudados. Seja por meio do cordel, das redes sociais ou de trabalhos acadêmicos, precisamos registrar e divulgar essas memórias. Com elas, provamos que a população negra sempre lutou por seus direitos, provamos que as mulheres negras sempre foram protagonistas dos movimentos negro e de mulheres e que nunca se 
omitiram ou saíram das trincheiras. Afinal, essas mulheres são espelhos e exemplos do que todas as meninas e jovens negras podem ser. (Arraes, 2015)

O objetivo manifesto da cordelista no texto em questão é "fazer com que essas mulheres negras sejam conhecidas e seus feitos sejam estudados". A autora busca chamar a atenção dos/das estudiosos/as para a necessidade de aprofundar as pesquisas sobre essas mulheres. Além disso, ela acredita que essas experiências de luta possam servir de referência para meninas e jovens negras nos dias de hoje.

Com base na leitura e nas discussões do artigo de Jarid, solicitamos que os/as estudantes elaborassem uma reflexão acerca das questões levantadas pela autora em seu artigo, como estas:

Nós, brasileiros, passamos vários anos na escola aprendendo sobre todos os detalhes das vidas de Dom Pedro I e II. Na televisão, os imperadores viram protagonistas de minisséries, enquanto os atores e atrizes negros são reduzidos a papéis de escravos sem profundidade. Grandes lutadores como Zumbi dos Palmares, Dragão do Mar e José Luiz Napoleão, são pouco mencionados. Aliás, eles são lembrados apenas no mês de novembro, em razão do Dia da Consciência Negra; mas as mulheres negras, que contribuíram de tantas formas na luta contra a escravidão e nas conquistas sociais do Brasil, nem sequer são mencionadas. (Arraes, 2015)

Essa atividade, como nos foi revelado, representou um primeiro contato dos/das estudantes com a história das mulheres negras, já que temas como “o que é a História", "o tempo histórico", “o que são fontes históricas" e "a economia e a sociedade colonial" já haviam sido abordados nas aulas anteriores. Após as discussões suscitadas pela leitura do artigo, os/as estudantes deveriam elaborar, individualmente, um texto como base no "roteiro básico para desenvolvimento do trabalho" (Anexo I).

Vejamos alguns registros, começando pela Estudante 1:

Infelizmente não estudamos a história das mulheres negras que são tão importantes para a história do Brasil. Isso porque elas contribuíram muito, de várias formas, na luta contra a escravidão e nas conquistas sociais do Brasil. Eram líderes inteligentes, com grande capacidade estratégica, imensa coragem e jamais se 
conformaram com o racismo. Essas mulheres servem como exemplo para toda a juventude brasileira, principalmente para as meninas negras, pois lhes falta referência histórica.

A estudante concordou com as reflexões de Jarid Arraes sobre a ausência das mulheres negras na história. Além disso, apontou a importância de elas servirem como referência para as meninas negras, demonstrando o seu papel nas lutas contra a escravidão e nas conquistas sociais da população negra brasileira. Em seu registro, a estudante destacou nas mulheres uma série de atributos geralmente identificados com o universo masculino, como liderança, inteligência, coragem e inconformismo. Sobressai no texto da estudante o desejo de igualdade entre homens e mulheres, brancos/as e negros/as.

O Estudante 2 anotou que "já havia conhecido Zumbi dos Palmares e outros nomes citados no texto, mas do gênero masculino", e conclui que "a história não cita muita coisa sobre as suas aliadas em suas batalhas". Outros/ as estudantes da turma reafirmaram o fato de desconhecerem a história das mulheres negras citadas por Jarid Arraes (Dandara dos Palmares, Tereza de Benguela, Luísa Mahin, Tia Simoa) e reconheceram que os meios de comunicação de massa, entre eles a televisão, deveriam divulgar mais a história das lutas contra a escravidão e por maior igualdade empreendidas por homens e mulheres negros/as. Também notamos esse desejo no texto produzido pelo Estudante 3:

O texto de Jarid Arraes denuncia os problemas da escravidão. Negros e negras raramente são citados, na história do Brasil, nas escolas. Raramente falam dos heróis da escravidão, relatando o que realmente acontecia. Nunca mencionam os fatos como a coisa vergonhosa que foi a escravidão. Antes desse texto, eu nunca havia estudado ou ouvido falar sobre essas personagens negras ... Sei que existem trabalhos para o resgate da identidade e da importância dos negros na história do Brasil, mas isso não é muito divulgado. Essas ações deveriam ter um alcance maior e em todas as classes e para todas as pessoas. A televisão deveria ter um papel mais efetivo nesse trabalho, pois alcança todas as pessoas.

Percebemos nos textos elaborados pelos/as estudantes em geral, e nos fragmentos aqui apresentados em particular, que se identificaram com a postura de Jarid Arraes quando ela denuncia a ausência da história das mulheres 
negras e a necessidade de se discutir esses temas em sala de aula e na sociedade em geral. Para avaliar essa recepção da proposta da autora, temos de levar em conta uma característica presente na produção escrita de estudantes que retornam para a escola depois de muito tempo afastados da instituição: nossa experiência de sala de aula, em turmas de EJA, indica que tendem a reproduzir o que leem. Assim, para que se possa chegar a uma produção textual mais autoral, é necessário realizar várias atividades de escrita. ${ }^{3}$

Após a discussão do artigo de Jarid Arraes, planejamos a introdução do trabalho com alguns cordéis escritos pela mesma escritora, nos quais são relatadas histórias de mulheres negras que tiveram papel de protagonistas em diferentes espaços e contextos da história do Brasil, entre os séculos XVII e XX. Para isso, compramos, utilizando o e-mail fornecido pela autora em seu blog na internet, alguns exemplares de cordéis que distribuímos entre os/as estudantes.

\section{A CORDELISTA E SEUS TRABALHOS: \\ O USO DE CORDÉIS NO ENSINO DE HISTÓRIA}

O uso da literatura de cordel nas aulas de história ainda é algo pouco problematizado ou mesmo registrado. Ao escolhermos trabalhar com a literatura de cordel intencionávamos romper com a prática que prevalecia em nossas aulas, de apresentar aos estudantes textos fotocopiados. Com os cordéis, possibilitamos aos estudantes o contato com materiais originais e com um gênero textual diferente dos que vínhamos utilizando até então. Tivemos o cuidado de apresentar para os/as estudantes, mesmo que brevemente, o que diferencia um texto histórico de um texto literário - no caso, a literatura de cordel. Como já demonstrado, a relação "entre História e Literatura é um assunto polêmico e desafiador. Numerosas discussões no âmbito acadêmico sugerem encontros e desencontros entre essas formas de apresentar o ser humano e as relações sociais dele com o mundo que o cerca" (Abud; Silva; Alves, 2010, p.43). No espaço do presente artigo não temos como aprofundar esse tema.

As turmas de EJA do CAp/UFRGS não utilizam livros didáticos. É de responsabilidade dos/das professores/as produzir e reproduzir os materiais a serem empregados em suas aulas. Ao lançarmos mão da literatura de cordel estamos possibilitando aos nossos/as estudantes o contato com um gênero 
literário relacionado à cultura popular nordestina. Nessa região, a literatura de cordel por muito tempo foi chamada de "literatura de folhetos". Sobre suas origens, Jairo Carvalho do Nascimento esclarece que:

A literatura de cordel, narrativa poética construída em versos, surgiu na Europa. Foi trazida para o Brasil pelos portugueses, no século XVII. Em terras brasileiras, desenvolveu-se na região Nordeste, onde surgiram as primeiras tipografias no final do século XIX. Os pioneiros nesse tipo de expressão poética foram Leandro Gomes de Barros, Francisco das Chagas e João Martins de Athayde, principais nomes da primeira metade do século XX. Seus objetos de inspiração poética são variados, versam desde temas do imaginário medieval (histórias de reis, príncipes e princesas, de dragões, de animais encantados etc.), até assuntos reais da história do Brasil e do mundo. (Nascimento, 2005, p.2)

Ao trabalhar com temas da história do Brasil por meio da literatura de cordel buscamos despertar nos/nas estudantes o interesse em conhecer um pouco mais sobre a cultura e sobre a história do Brasil.

A literatura de cordel constitui traço muito rico da cultura popular no Nordeste brasileiro. O cordel, segundo Maria Ângela de Faria Grillo (2003, p.116), tem "testemunhado fatos da história do Brasil, revelando a preocupação dos poetas e ouvintes com o mundo ao seu redor". O cordel tem espaço em diversas áreas da cultura brasileira, como nos lembra Marco Haurelio:

A importância da literatura de cordel vai muito além do volume de folhetos produzidos em mais de um século de existência. O seu reaproveitamento em outras manifestações artísticas, as releituras e apropriações feitas por poetas de outras searas, são indicadores de sua presença na cena cultural brasileira. (Haurelio, 2013, p.151)

Os cordéis que utilizamos em nossas aulas foram escritos recentemente, entretanto, trabalham personagens de tempos distantes e que pouco ou nunca são lembradas pela historiografia. Percebemos que o uso de cordéis e as histórias ali contidas mexeram com o sentimento dos/das estudantes, na medida em que trouxeram nas suas rimas histórias que tocavam, poesia que mobilizava os sentimentos dos leitores. Um exemplo pode ser destacado do cordel sobre Dandara dos Palmares: 
Nenhuma mulher é frágil

Temos de Dandara o punho

Que mantemos bem erguido

Sendo nosso testemunho

De que a história feminina

Não é feita pra rascunho

(Arraes, s.d., p.7)

Nesse, como em diversos outros trechos dos cordéis empregados, pudemos perceber que não estávamos somente fazendo um resgate da figura histórica negra feminina, mas proporcionávamos também um espaço para o sentir, para a reflexão, construindo um conhecimento acerca do protagonismo de mulheres negras na história do Brasil.

\section{A Historiografia SObRe AS MUlHeres Negras No Brasil}

Antes de apresentar os cordéis para os/as estudantes, buscarmos ampliar os nossos conhecimentos sobre a maneira como a historiografia tem abordado a participação das mulheres negras na história do Brasil. Uma síntese do que se encontrou está narrada a seguir. Esse conhecimento foi utilizado durante a aula com os cordéis para complementar as informações apresentadas pelos/as estudantes.

Desde pelos menos o final dos anos 1980 a questão da mulher escravizada tem sido abordada pela historiografia. Em 1988, Sonia Maria Giacomini publicou o livro Mulher e escrava: uma introdução histórica ao estudo da mulher negra no Brasil. Nessa obra a autora criticou os estudos que "fazem da negra algo a ser invejado pela senhora branca" pelo fato de que, no entender de alguns autores, no "âmbito do cativeiro as mulheres negras eram mais independentes [que as brancas]" (Giacomini, 1988, p.88).

No livro de Sonia Maria Giacomini analisam-se, entre outros temas, a violência da escravidão, o papel da mulher escrava na família, a mulher negra enquanto objeto sexual e as relações entre senhoras e escravizadas na sociedade brasileira do século XIX. A resistência à escravidão e a participação das mulheres nas lutas emancipatórias não foram abordadas. 
Em estudos mais recentes, a historiografia tem abordado as mulheres, brancas e negras, como uma categoria geral (as escravizadas, as mulheres negras, as mulheres brancas, as mulheres jovens, as mães, as libertas, a mulher imigrante e as mulheres chefes de família, entre outras). É o caso de publicações voltadas ao grande público, mas escritas por historiadoras, como Mulheres no Brasil Colonial (Del Priore, 2000), História das mulheres no Brasil (Del Priore, 2004) e Nova História das mulheres no Brasil (Bassanezi; Pedro, 2012). Essas publicações não se debruçam sobre personagens paradigmáticas, nem se referem às mulheres que são tratadas nos trabalhos de Jarid Arraes.

As mesmas mulheres, no entanto, podem ser encontradas em outras obras acadêmicas como Submissão e Resistência: a mulher na luta contra a escravidão, de Lucia Barros Mott (1991), Mulheres Negras do Brasil (Schumaher; Brazil, 2007), na Enciclopédia Brasileira da Diáspora Africana (Lopes, 1991) e no Dicionário da escravidão negra no Brasil (Moura, 2004). O diálogo entre essas obras e os cordéis será apresentado adiante.

Em nossas aulas, utilizamos seis cordéis que relatam histórias de mulheres que viveram em diferentes períodos da história brasileira. Do período colonial utilizamos os cordéis que discorrem sobre Aqualtune, Dandara dos Palmares e Tereza de Benguela. Do período do Brasil Império empregamos o cordel que narra a história de Luisa Mahin, ${ }^{4}$ e do período republicano adotamos os cordéis de Tia Simoa e Carolina Maria de Jesus.

O levantamento bibliográfico que realizamos nos indicou que, ao contrário das demais personagens mencionadas, não existem registros históricos da existência de uma mulher chamada Dandara dos Palmares. Após depararmos com essa informação, nosso impulso inicial foi o de excluir esse cordel da atividade. Porém, diante da força do mito de Dandara e da importância dessa figura feminina para o movimento negro, optamos por mantê-lo e informar os/as estudantes sobre a dificuldade de se comprovar documentalmente a sua existência. Essa suposta dificuldade ou ausência de fontes apresentou-se como oportunidade para retomar as discussões feitas em aulas anteriores sobre a importância dos documentos para a escrita da história.

Sobre Dandara dos Palmares a Enciclopédia Brasileira da Diáspora Africana (Lopes, 1991, p.227-228), escrita pelo pesquisador da cultura afro-brasileira e compositor Nei Lopes, nos informa ser "personagem lendária” da história do Quilombo dos Palmares, situado na antiga capitania de 
Pernambuco, hoje estado de Alagoas: “celebrada como a grande liderança feminina da epopeia quilombola, teria morrido quando da destruição de Macaco (nome do principal quilombo Palmarino)". Nei Lopes ressalta que a existência de Dandara está "envolta em uma aura de lenda".

Também ligada ao quilombo dos Palmares está a personagem Aqualtune. Existem indícios de que Aqualtune tenha sido uma das mulheres que exerceram influência no quilombo. A maior parte dos registros históricos sobre essa experiência histórica resulta de denúncias ou relatos de expedições punitivas, que tentavam destruir o quilombo. Quase nada existe de testemunho dos próprios quilombolas (Schumaher; Brazil, 2006, p.82). Segundo a historiadora Maria Lucia de Barros Mott, a tradição guarda o nome dessa mulher que teria sido ligada à elite palmarina. Aqualtune era mãe de Ganga Zumba e avó de Zumbi. Alguns historiadores consideram-na personagem lendária. Aqualtune era filha do rei do Congo e comandou um exército de 10 mil homens na luta contra os soldados do reino de Java. Derrotada, foi levada como escrava para um navio negreiro e desembarcada no Recife. Foi vendida para um engenho e, algum tempo depois, fugiu para o Quilombo dos Palmares onde, ao lado de Ganga Zumba, organizou um Estado negro (Mott, 1991, p.45).

Tereza de Benguela, por sua vez, liderou o Quilombo Quariterê, em Vila Bela da Santíssima Trindade, no estado do Mato Grosso, no século XVIII. Durante o seu governo, o quilombo contou com agricultura desenvolvida, produzia algodão e vários alimentos; possuía teares com os quais fabricava tecidos grosseiros, que possivelmente eram vendidos para fora do quilombo, assim como excedentes alimentares (Mott, 1991, p.45). Em um ataque da coroa portuguesa ao quilombo, Tereza foi presa. Não aceitando a condição de escrava, suicidou-se. O dia 25 de julho no Brasil é oficialmente o dia de Tereza de Benguela, uma data para enfatizar a luta das mulheres negras no país.

Em 1835, na Bahia, Luiza Mahin e outras quitandeiras foram apontadas como corresponsáveis pela revolta dos malês, pois forneciam comida e conspiravam com as lideranças do levante (Schumaher; Brazil, 2006, p.65). Sobre a vida de Luiza ficamos sabendo algumas poucas passagens mediante escritos de seu filho, o poeta Luís Gama. Ele nos informa que Luiza Mahin se intitulava princesa africana, da região dos mahi, localizada no Daomé (hoje Benin). Muitos estudiosos acreditam que Luiza Mahin nasceu em Salvador. Sabe-se que em 1812 já era livre, que fazia de sua casa um refúgio para rebelados e que 
participou da chamada Revolta dos Malês, um dos movimentos negros mais emblemáticos da história da escravidão africana no Brasil. O levante irrompeu em Salvador, na madrugada de 24 de janeiro de 1835, liderado por escravos africanos islamizados. Luiza, por ter sido quitandeira, dispunha de grande mobilidade pelo fato de conhecer as vielas, ruas e os mais diversos recônditos da capital baiana. Atuou como articuladora dos revoltosos, trocando bilhetes entre eles, sob a proteção de crianças que, a pretexto de comprar as iguarias da quitandeira, ajudavam-na em sua missão secreta. Se os planos dos malês saíssem dentro do esperado, ela seria nomeada a rainha da Bahia rebelde. Entretanto, o motim foi debelado às vésperas do dia programado. Seus líderes foram perseguidos e castigados com severidade, mas Luiza conseguiu fugir para o Rio de Janeiro, onde foi presa e, possivelmente, deportada para a África (Schumaher; Brazil, 2006, p.95).

Nos livros por nós pesquisados não encontramos referências sobre a história de Tia Simoa. Foi num verbete do Dicionário da Escravidão Negra no Brasil, dedicado a José Luiz Napoleão, líder da greve dos jangadeiros no Ceará, em 1881, que ficamos sabendo da existência e participação de Tia Simoa naquele evento. Com o marido, Luiz Napoleão, ela aliciou pessoas e deu impulso à greve dos jangadeiros que impediu o embarque de escravizados para outras províncias do Império (Moura, 2004, p.286).

A escritora Carolina Maria de Jesus, finalmente, nasceu no período pós-abolição, em 1914. Era descendente de escravos. Morou em uma favela de São Paulo e coletava papel com o pai para o sustento dos irmãos. Em uma caderneta encontrada no lixo, começou a relatar seu cotidiano penoso e a denunciar a realidade excludente na qual viviam as populações negras na favela. Em 1960, teve seu diário publicado por um jornalista, com o título Quarto de despejo. Vendeu mais de 100 mil copias, traduzidas para 29 idiomas. Publicou também Casa de Alvenaria (1961), Pedaços da Fome (1963), Provérbios (1963) e Diário de Bitita (póstumo, 1982), entre outros (Lopes, 1991, p.358-359).

Após conhecer um pouco mais sobre essas mulheres, iniciamos a atividade com os estudantes. Para isso, entregamos um pequeno texto contendo breve história do cordel, sua origem e a importância como veículo de divulgação de informações. Além disso, disponibilizamos um roteiro de leitura no qual indicamos algumas informações que deveriam ser apresentadas no trabalho escrito (Anexo II). 
A turma foi dividida em seis grupos. Cada grupo ficou responsável por um dos cordéis por nós selecionados. Disponibilizamos os cordéis para que eles realizassem o trabalho escrito e preparassem as suas apresentações orais. Essa etapa aconteceu em sala de aula e extraclasse. Realizada essa atividade, os grupos socializaram com os demais estudantes da turma o que aprenderam nos livretos e nas pesquisas realizadas sobre as personagens. Após cada apresentação os professores buscavam aprofundar os conhecimentos sobre as personagens estudadas. Foi nesse momento que informamos sobre a falta de fontes históricas que comprovem a existência de Dandara dos Palmares. Apesar dessa ausência de registros, ressaltamos, o mito de Dandara é muito forte, principalmente no movimento negro.

As faltas e desistências são muito frequentes entre estudantes da EJA, algo que observamos ao longo das aulas aqui relatadas. No dia da apresentação, apenas cinco grupos compareceram: Grupo 1, Luisa Mahin; Grupo 3, Carolina Maria de Jesus; Grupo 4, Tereza de Benguela; Grupo 5, Aqualtune; Grupo 6, Dandara dos Palmares. O Grupo 2, que discorreria sobre Tia Simoa, não se apresentou, cabendo aos professores a tarefa de relatar a história dessa personagem. As apresentações não foram realizadas em ordem cronológica. Deixamos que os/as estudantes se organizassem para decidir a ordem das apresentações.

A socialização dos trabalhos foi realizada na forma de seminário. Todos/ as os/as estudantes sentaram em círculo. Os cinco grupos que apresentaram desenvolveram um material escrito sobre suas personagens. O primeiro grupo, ao apresentar o cordel de Tereza de Benguela, emocionou-se. O estudante 4 verbalizou que se lembrava de ter estudado, quando mais jovem, sobre a história da colonização do Brasil. Disse ainda que, em razão da abordagem empregada na época, pensava que índios e negros tinham papel de figurantes nesse processo, e que se sentia grato por, graças às aulas da EJA, ter passado a enxergar essa história de outra maneira.

O estudante 5 disse estar triste por até aquele momento nunca ter ouvido falar em nenhuma daquelas personagens tão importantes "da história negra de resistência”. Esse aluno é negro e afirmou que se envergonhava por nunca ter podido falar dessas mulheres para suas filhas, e que, a partir das nossas aulas, seria algo que passaria para elas. Da sua intervenção durante a apresentação registramos ainda este comentário: "Por ser negro, deveria ter a 
obrigação de saber toda essa história tão rica e sofrida. Não tinha o menor conhecimento dessas heroínas até então anônimas para mim, mulheres que lutaram de igual para igual com seus companheiros negros por liberdade, respeito e igualdade".

As falas dos/das estudantes giraram muito em torno da questão do desconhecimento sobre essas personagens, o que nos faz verificar que ainda sobressai uma história política eurocêntrica e androcêntrica nas salas de aula e nos meios de comunicação.

Os membros do Grupo 6, que apresentou a leitura do cordel sobre Dandara dos Palmares, registraram em seu trabalho escrito: "Foi importante estudar a história dessas mulheres, com esse estudo descobrimos que as mulheres negras não foram apenas escravas submissas e conformadas, foram sim protagonistas e influentes nos movimentos de liberdade e resistência contra a discriminação".

Os trabalhos escritos e as falas durante as apresentações continham esse tom de descoberta e de desconforto. Em seus registros escritos ficou uma sensação de inconformidade por terem percebido somente nessa altura de suas vidas o quanto as histórias dessas mulheres negras são relevantes. Desagradava-os o fato de que, até então, nunca tinham lido ou ouvido falar de Aqualtune, Dandara dos Palmares, Tereza de Benguela, Luisa Mahin, Tia Simoa e Carolina Maria de Jesus.

\section{CONSIDERAÇÕES FINAIS}

Neste artigo relatamos a realização de uma experiência de ensino na qual se utilizou um artigo divulgado na internet e cordéis para trabalhar com a temática do protagonismo das mulheres negras na história do Brasil.

A atividade foi desenvolvida numa turma do primeiro ano do ensino médio da Educação de Jovens e Adultos (EJA). Constatamos inicialmente que os/as estudantes afirmavam desconhecer a presença de mulheres negras na história do Brasil. Prevalecia na turma um conhecimento histórico no qual sobressaíam as datas históricas, alguns acontecimentos políticos e os chamados heróis nacionais, em sua maioria homens brancos que ocupavam postos de comando. 
A maioria dos/das estudantes havia parado de estudar antes dos anos 1990. Ou seja, num período anterior à criação da Lei de Diretrizes e Bases da Educação Nacional (LDB) e da Lei 10.639/03, sancionada em 2003, a qual estabeleceu a obrigatoriedade do Ensino de História e Cultura Afro-Brasileira e Africana no currículo da Educação Básica. Essas leis resultaram das lutas do movimento negro que, desde os anos 1970, demandava a inserção dessas temáticas em sala de aula.

Também os historiadores e historiadoras ligados à História das Mulheres e à história das relações de gênero têm reivindicado a inserção dessas temáticas na Educação Básica, visando combater as desigualdades existentes entre homens e mulheres e os preconceitos de gênero. Apesar dessa demanda, ainda se verifica nos livros didáticos de história a divulgação de uma história na qual as mulheres negras aparecem como vítimas da escravidão e do patriarcalismo, deixando de fora uma história em que elas atuam como protagonistas das lutas contra várias formas de opressão, entre as quais as de gênero e de classe.

Desenvolvemos a atividade relatada em dois momentos. Iniciamos com a leitura de um artigo escrito pela jornalista e cordelista Jarid Arraes, intitulado "Heroínas negras na história do Brasil". Um roteiro de leitura foi elaborado para auxiliar os/as estudantes nessa tarefa.

Os/as estudantes se identificaram com as ideias apresentadas por Jarid Arraes, com sua denúncia da ausência das mulheres negras na história e sobre a necessidade de se discutir esses temas em sala de aula.

Ao possibilitarmos o contato dos/das estudantes com a literatura de cordel estávamos permitindo seu acesso a um gênero literário que representa a cultura popular nordestina. Pudemos perceber que a leitura dos cordéis mexeu com sua sensibilidade e favoreceu a aprendizagem da temática proposta. A leitura estimulou nos/nas estudantes o desejo de conhecer mais acerca da participação das mulheres negras na história do Brasil, não somente como vítimas, mas como referências de lutas e de conquistas.

\section{REFERENNCIAS}

ABUD, Kátia M.; SILVA, André C. de M.; ALVES, Ronaldo C. Ensino de História. São Paulo: Cengage Learning, 2010.

ALMEIDA, Marlon Mello de. Imagens femininas na literatura de cordel. Dissertação (Mestrado em Letras) - Universidade Federal do Rio Grande do Sul (UFRGS). Porto Alegre, 1994. 
BRASIL. Ministério da Educação/Secretaria da Educação Básica. História. Catálogo do Programa Nacional do Livro Didático para o Ensino Médio: PNLEM/2008/ Secretaria da Educação Básica, Fundo Nacional de Desenvolvimento da Educação. Brasília, 2007.

BRAZIL, Érico Vital; SCHUMAHER, Schuma. Mulheres Negras do Brasil. São Paulo: Ed. Senac, 2006.

CAMPOS, C. R. P. Oficina Congado, coroação do rei Congo. Cadernos do Aplicação, Porto Alegre, v.25, n.1, 2012. Disponível em: http://seer.ufrgs.br/index.php/ CadernosdoAplicacao/article/view/34652; Acesso em: 3 mar. 2017.

CARVALHO, Rayssa Andrade; ROCHA, Solange Pereira. Movimento de mulheres negras e a luta pela afirmação dos direitos humanos no Brasil. Cadernos Imbondeiro, João Pessoa, v.2, n.1, 2012. Disponível em: http://periodicos.ufpb.br/index.php/ci/ article/viewFile/14252/8826; Acesso em: 11 out. 2016.

CASCUDO, Luís da Câmara. Dicionário do Folclore Brasileiro. São Paulo: Global, 2001.

CHARTIER, Roger. Debate: Literatura e História. Topoi, Rio de Janeiro, n.1, p.197216, 1999.

CURRAN, Mark J. História do Brasil em Cordel. São Paulo: Edusp, 2001.

DEL PRIORE, Mary. História das mulheres no Brasil. São Paulo, Contexto, 2004. . Mulheres no Brasil colonial. São Paulo: Contexto, 2000.

DIAS, Maria Odila. Escravas: resistir e sobreviver. In: PINSKY, Carla Bassanezi; PEDRO, Joana Maria. Nova História das Mulheres no Brasil. São Paulo: Contexto, 2012.

GIACOMINI, Sonia Maria. Mulher e escrava: uma introdução histórica ao estudo da mulher negra no Brasil. Petrópolis: Vozes, 1988.

GRILLO, Maria Ângela de Faria. A literatura de cordel na sala de aula. In: ABREU, Martha; SOIHET, Rachel (Org.) Ensino de história: conceitos, temáticas e metodologia. Rio de Janeiro: Casa da Palavra, 2003.

HAURÉLIO, Marco. Literatura de cordel: do sertão à sala de aula. São Paulo: Paulus, 2013.

LEOPOLDINO, Maria Aparecida. A leitura de textos literários no ensino de história escolar: entrelaçando percursos metodológicos para o trato com os conceitos de tempo e espaço. Revista História Hoje, v.4, n.8, p.130-151, 2015. Disponível em: https://rhhj.anpuh.org/RHHJ/article/view/189/145; Acesso em: 14 ago. 2017.

MISTURA, Letícia; CAIMI, Flávia Eloisa. O (não) lugar da mulher no livro didático de história: um estudo longitudinal sobre relações de gênero e livros escolares (1910-2010). Aedos, Porto Alegre, v.7, n.16, p.229-246, 2015. Disponível em: http://seer.ufrgs.br/index.php/aedos/article/view/57019; Acesso em: 24 maio 2017. 
MOTT, Maria Lucia de Barros. Submissão e resistência: a mulher na luta contra a escravidão. São Paulo: Contexto, 1991.

MOURA, Clóvis. Dicionário da escravidão negra no Brasil. São Paulo: Edusp, 2004.

NASCIMENTO, Jairo Carvalho. A literatura de cordel no ensino de História: reflexões teóricas e orientações metodológicas. In: SIMPÓSIO NACIONAL DE HISTÓRIA, Anpuh, 23., 2005, Londrina.

NEPOMUCENO, Bebel. Mulheres negras: protagonismo ignorado. In: PINSKY, Carla Bassanezi; PEDRO, Joana Maria. Nova História das Mulheres no Brasil. São Paulo: Contexto, 2012.

OLIVA, Anderson Ribeiro. Entre máscaras e espelhos: reflexões sobre a Identidade e o ensino de História da África nas escolas brasileiras. Revista História Hoje, v.1, n.1, p.29-44, 2012. Disponível em: https://rhhj.anpuh.org/RHHJ/article/view/4/5; Acesso em: 24 maio 2017.

PEREIRA, Júnia Sales; ROZA, Luciano Magela. O ensino de história entre o dever de memória e o direito à história. Revista História Hoje, v.1, n.1, p.89-110, 2012. Disponível em: https://rhhj.anpuh.org/RHHJ/article/view/4/5; Acesso em: 24 maio 2017.

PERES, Elena Pajaro. Carolina Maria de Jesus, insubordinação e ética numa literatura feminina de diáspora. In: ASSIS, Maria Elisabete Arruda de; SANTOS, Taís Valente dos (Org.) A memória feminina: Mulheres na história, história de mulheres. Recife: Fundação Joaquim Nabuco; Massangana, 2016. Disponível em: http:// www.museus.gov.br/wp-content/uploads/2017/03/Mem\%C3\%B3ria-femininamulheres-na-hist\%C3\%B3ria-hist\%C3\%B3ria-de-mulheres.pdf; Acesso em: 24 maio 2017.

PINSKY, Carla Bassanezi; PEDRO, Joana Maria. Nova História das Mulheres no Brasil. São Paulo: Contexto, 2012.

SCHUMAHER, Schuma; BRAZIL, Érico Vital. Mulheres Negras do Brasil. Rio de Janeiro: Senac Nacional, 2007.

\section{Artigo e cordéis de Jarid Arraes trabalhados em sala de aula}

ARRAES, Jarid. Heroínas Negras na História do Brasil. Fórum, Porto Alegre, abr. 2015. Disponível em: http://www.revistaforum.com.br/questaodegenero/2015/04/17/heroinas-negras-na-historia-brasil/; Acesso em: 10 out. 2016.

Aqualtune. Carolina Maria de Jesus. Dandara dos Palmares. Luisa Mahin. Tereza de Benguela. Tia Simoa. Cordéis (todos s.d.) 


\section{ANEXO I \\ UNIVERSIDADE FEDERAL DO \\ RIO GRANDE DO SUL - COLÉGIO DE APLICAÇÃO}

Professor Vanderlei Machado - Professora de Educação Continuada:

Ana Paula Zini - História - EJA EM1

\section{Heroínas negras na história do Brasil}

Jarid Arraes

$\mathrm{Na}$ história do Brasil, conta-se muito pouco a respeito das mulheres negras. Na escola, são pouquíssimas as aulas que citem as grandes guerreiras e líderes quilombolas, ou que simplesmente mencionem a existência das mulheres negras para além da escravidão. Em um país em que a escravidão não é retratada como uma vergonha para a nação - pelo contrário, ainda se insiste que a população negra não lutou contra esse quadro -, isso não é nenhuma surpresa.

Nós, brasileiros, passamos vários anos na escola aprendendo sobre todos os detalhes das vidas de Dom Pedro I e II. Na televisão, os imperadores viram protagonistas de minisséries, enquanto os atores e atrizes negros são reduzidos a papéis de escravos sem profundidade. Grandes lutadores como Zumbi dos Palmares, Dragão do Mar e José Luiz Napoleão são pouco mencionados. Aliás, eles são lembrados apenas no mês de novembro, em razão do Dia da Consciência Negra; mas as mulheres negras, que contribuíram de tantas formas na luta contra a escravidão e nas conquistas sociais do Brasil, nem sequer são mencionadas.

Por conta disso, as garotas negras crescem achando que não há boas referências intelectuais e de resistência nas quais possam se espelhar. Para descobrir seus referenciais, é preciso que se mergulhe em uma pesquisa individual, muitas vezes solitária, juntando peças de um enorme quebra-cabeça para no fim descobrir que pouquíssimo foi registrado a respeito de mulheres como Dandara dos Palmares ou Tereza de Benguela - importantes líderes quilombolas. Devido ao machismo, é muito difícil encontrar registros da história das mulheres. Ainda hoje, poucas mulheres, mesmo entre as brancas ou 
europeias, são citadas e celebradas por suas conquistas. No entanto, quando essas mulheres são negras, a negligência é ainda maior. Em um país onde mais de $50 \%$ da população é negra, a situação desse quadro é absurda.

Mesmo com os esforços racistas para apagar a história das mulheres negras, racismo nenhum será capaz de enterrar a memória de ícones como Luísa Mahin e Tia Simoa. Mulheres negras inteligentes, com grande capacidade estratégica, imensa coragem e ímpeto de transformação, que jamais se conformaram ou se dobraram diante do racismo e da misoginia; pelo contrário, lutaram e deram suas vidas para que mulheres negras como eu pudessem viver em liberdade e escrever, ocupando espaços que, ainda hoje, nos são de difícil acesso.

Nosso papel é fazer com que essas mulheres negras sejam conhecidas e seus feitos sejam estudados. Seja por meio do cordel, das redes sociais ou de trabalhos acadêmicos, precisamos registrar e divulgar essas memórias. Com elas, provamos que a população negra sempre lutou por seus direitos, provamos que as mulheres negras sempre foram protagonistas dos movimentos negro e de mulheres e que nunca se omitiram ou saíram das trincheiras. Afinal, essas mulheres são espelhos e exemplos do que todas as meninas e jovens negras podem ser.

Fonte: http://www.revistaforum.com.br/questaodegenero/2015/04/17/ heroinas-negras-na-historia-brasil/

\section{Roteiro básico para desenvolvimento do trabalho}

- Qual a ideia principal do texto de Jarid Arraes? Sobre quais personagens ela escreve?

- Lendo sobre a escravidão no Brasil, você já havia ouvido falar sobre algum nome citado no texto? Qual a relevância dessas mulheres negras para a história do Brasil?

Observação: O Grupo deve aprofundar os temas solicitados realizando pesquisas na internet e na biblioteca. Porém, não se esqueçam de informar o endereço dos sites e as referências bibliográficas dos livros pesquisados. 


\section{ANEXO II \\ UNIVERSIDADE FEDERAL DO \\ RIO GRANDE DO SUL - COLÉGIO DE APLICAÇÃO}

Professor Vanderlei Machado - Professora de Educação Continuada:

Ana Paula Zini - História - EJA EM1

\section{Literatura de Cordel}

Cordel: denominação dada em Portugal e difundida no Brasil, referente aos folhetos impressos, compostos em todo o Nordeste e depois divulgados pelo país. Em Portugal dizem "literatura de cordel" porque os livrinhos eram expostos à venda cavalgando um barbante, como ainda acontece em certos pontos do Brasil.

Para Luís da Câmara Cascudo, a característica da literatura de cordel é a sua destinação gráfica, circulando em panfletos impressos, desde a segunda metade do século XIX, não se conhecendo nada publicado anteriormente a 1870 (Cascudo, 2001).

A literatura de cordel é uma poesia folclórica. Consiste basicamente em longos poemas narrativos, chamados "romances" ou "histórias", impressos em folhetins ou panfletos que falam de amores, sofrimentos ou aventuras, num discurso heroico de ficção (Curran, 2001, p.17).

Segundo Mark Curran o cordel é considerado como um jornalismo popular, que divulga notícias do dia. Alguns teóricos da comunicação consideram o cordel como uma crônica poética e história popular do século XX (Curran, 2001, p.24).

O cordel serve, também, em vários casos, de avalista para as notícias publicadas pelos jornais ou transmitidas pelo rádio e pela televisão porque, muitas vezes, o leitor lhe dá mais crédito. Isso é bastante compreensível; afinal, o poeta que escreve é um líder natural da comunidade, está em contato direto com seu público, vive no meio dele, portanto o folheto não é uma coisa distante, fria, estranha, mera forma noticiosa ou emissão passageira.

$\mathrm{O}$ poeta apreende um acontecimento e o retransmite numa linguagem popular, dentro do campo de referência dos seus leitores. O texto cordeliano 
pode ser tanto um relato jornalístico quanto um comentário jocoso ou sarcástico do dia.

\section{REFERÊNCIAS:}

CASCUDO, Luís da Câmara. Dicionário do Folclore Brasileiro. São Paulo: Global, 2001.

CURRAN, Mark J. História do Brasil em Cordel. São Paulo: Edusp, 2001.

\section{Roteiro para a oficina:}

\section{As Heroínas Negras no Brasil representadas pela literatura de cordel}

- O que é literatura de cordel? Onde surgiu e como veio para o Brasil? Em que região brasileira mais se popularizou?

- Pesquise na internet: quem é Jarid Arraes? Com quais temáticas de cordéis a autora trabalha e por quê?

- Qual o nome da personagem do cordel trabalhado? Quem era ela? Em que época viveu?

- De que lugar era? Morava onde nasceu? Como é relatada a sua vida? O que ela fazia? Você a definiria como uma heroína? Por quê?

- Você conhecia alguma das personagens trabalhadas por Jarid nos cordéis? Qual a importância de se buscar conhecer a história dessas mulheres?

\section{NOTAS}

${ }^{1}$ Agradecemos às professoras Luciana Rossato (Departamento e Programa de Pós-Graduação em História - Udesc) e Carla Simone Rodeghero (Departamento e Programa de Pós-Graduação em História - UFRGS) a leitura e os comentários ao texto.

${ }^{2}$ Jarid Arraes nasceu em Juazeiro do Norte, cidade localizada na região do Cariri, interior do Ceará, em 12 de fevereiro de 1991. É filha e neta de cordelistas e xilogravadores. Começou a publicar seus escritos aos 20 anos de idade, no blog Mulher Dialética. Logo passou a colaborar em blogs como o Blogueiras feministas e o Blogueiras Negras, e em 2013 se tornou colunista da revista Fórum, onde manteve o blog Questão de Gênero até fevereiro de 2016. Jarid morou em Juazeiro do Norte até 2014 e participou de coletivos regionais, como o Pretas Simoa (Grupo de Mulheres Negras do Cariri) e o FEMICA (Feministas do Cariri), o qual fundou. Em dezembro de 2014 mudou-se para São Paulo, onde passou a 
fazer parte da ONG Casa de Lua até o seu fechamento. Para mais informações sobre a biografia de Jarid Arraes consultar: http://jaridarraes.com/biografia/; Acesso em: 13 mar. 2017.

${ }^{3} \mathrm{Na}$ Educação de Jovens e Adultos (EJA) do Colégio de Aplicação da UFRGS, além das disciplinas de Português e Redação, os estudantes contam com a disciplina Projeto de Investigação (PI), na qual pesquisam um tema de seu interesse e devem apresentar, ao final do semestre, uma produção textual sobre o que foi pesquisado.

${ }^{4}$ No cordel aparece a grafia Luisa Mahin. Na maioria das obras consultadas, porém, o nome é grafado como Luiza Mahin. Utilizaremos a primeira forma para nos referirmos ao cordel, e a segunda quando estivermos dialogando com os demais autores.

Artigo recebido em 7 de julho de 2017. Aprovado em 16 de agosto de 2017. 